\title{
Cognitive realism and memory in Proust's madeleine episode
}

\section{Emily T. Troscianko}

\begin{abstract}
The famous 'madeleine episode' of Proust's In Search of Lost Time is investigated with reference to cognitive realism in the evocation of memory, by asking how this literary memory experience compares with the conceptualisation of memory in current cognitive science. Furthermore, what does close reading of the episode informed by current scientific findings and debates on memory and agency tell us about Proust's categorization of this memory event as involuntary memory, and his presentation of voluntary and involuntary memory as a distinct opposition? I show that the madeleine episode 1) corresponds partly to cognitive realities as documented by recent science and partly to prevalent expectations about cognition or its narration, and 2) undermines the neat voluntary/involuntary distinction it initially seems to illustrate. I suggest how these qualities may affect readers' responses to Proust's famously evocative object.
\end{abstract}

Keywords: Cognitive literary studies, free will, involuntary memory, memory studies, Proust, voluntary memory

Marcel Proust's In Search of Lost Time has a long history of cognitively orientated interpretation (e.g. O’Brien, 1970; Shepherd-Barr and Shepherd, 1998; Delacour, 2001; Utermohlen, 2002; Nalbantian, 2003; Ender, 2005), for this seminal twentieth-century text not only emphasizes the crucial role that the cognitive capacity of memory plays in making narration itself possible; it also evokes a form of memory previously under-recognized in memory research, 'involuntary memory'. This evocation has made 'Proust's madeleine' a shorthand for the vivid and emotionally powerful flooding-back of even very distant and 
long-dormant memories when tasting or smelling something from one's past: the madeleine is 'perhaps the most famous evocative object in all literature' (Turkle, 2007: 318).

\section{Methodological issues: Proustian memory, science, aesthetics, and folk psychology}

My aim is to elucidate the madeleine as an evocative object with reference to the episode's cognitive realism in the evocation of memory, by evaluating the extent to which memory in this episode corresponds to or differs from the cognitive realities of remembering, as understood by current science (and without value judgements or attributions of authorial intent). The article does not seek to elucidate the 'meaning' of the episode or indeed the novel. Instead, it explores the episode's textual features in relation to cognitive realities as currently emerging in scientific research, and in relation to evocations of memory elsewhere in the novel, and concludes by briefly hypothesising as to their possible effects on readers. The analysis is intended to propose conclusions beneficial to literary criticism, and also to suggest how memory studies might derive insights from a fuller understanding of the passage.

The madeleine episode is of course not the only significant instance of involuntary memory in the Search: the sequence of five instances in the final volume, Finding Time Again, most of which are triggered by sensory cues (stimuli to remembrance) such as the sensation of uneven flagstones or the feel of a stiffly starched napkin, constitute the major impetus to the focalizer's ${ }^{2}$ new understanding of involuntary memory and its potential. Beyond this key sequence of involuntary memories, the novel contains a wide range of other memory events. These include somatic memories, 'memories' based on hearsay, memories which have been interpreted as 'screen memories' in a psychoanalytical sense, and memories which are more fully voluntary in their retrieval. A recent word-count analysis of the novel finds 1,210 uses 
of terms relating to memory on 3,125 pages, and suggests that it contains 'a thorough analysis of at least 10 main topics on memory' (Bogousslavsky and Walusinski, 2009: 161). A full account of memory in the Search would have to include all these varying instantiations, but this article has a less ambitious scope: working outwards from a detailed examination of the madeleine episode allows us to draw conclusions about the nature of involuntary memory and its voluntary counterpart, in the novel and beyond.

Comparing this literary evocation of memory with scientific claims about memory may seem an overly literal response to a passage of great aesthetic as well as cognitive interest. However, a strict division between the aesthetic and the cognitive when considering literary artworks is impossible, given that any fictional text is created through cognition, textually evokes cognition in its characters, and achieves its effects only through the cognition of the reader. Indeed, the roots of the term 'aesthetics', in the Greek for perception, sensation, or feeling, mean that the cognitive is always at the heart of the aesthetic, broadly speaking. And the Search in particular is structured to such an extent by the workings of memory that none of the novel's more 'aesthetic' concerns - identity, time, beauty, love and sexuality, art and life, intellectual 'influence' - can easily be considered in isolation from cognitive issues. Themes other than memory cannot be discussed in detail here, but insights gained in this area may well have relevance to other themes: identity, the experience of time, and the relation between literary art and lived life.

Evelyne Ender (2005) argues for the importance of investigating cognition in the Search; she does so in two steps, both of which take account of the aesthetic angle. ${ }^{3}$ The first step invokes the scientific significance of Proustian memory: 
critics have suggested Proust's preference [for involuntary memory over voluntary] is motivated, above all, by aesthetic considerations: it enables him to organize his story around a striking revelation, a sort of epiphany. But the overwhelming response this model of remembrance has received among scientists tells us something else. [...] Proust emphasizes the physiological underpinnings of remembrance and changes the very definition of recollection. [...] With his stimulus-response model and his visionary idea that a mysterious chemistry produces remembrance, Proust opened new vistas for the scientific exploration of personal memory. (2005: 29)

The second step argues that Proustian memory is, in any case, inherently aesthetic: the rememberer's responses to memory events are rich in ways comparable to a viewer's response to visual art, or a listener's response to music. Memory in the Search is, Ender suggests, 'a dynamic process that emerges from and is sustained by an aesthetic impulse; it is creative in the fullest sense of the term' (2005: 43).

The first part of Ender's argument about Proust, cognition, and aesthetics can, however, entail over-emphasis of Proust's achievements as scientific. Drawing on work by Antonio Damasio, Marigold Linton, Israel Rosenfield, and Oliver Sacks, Ender sometimes foregrounds the notion that Proust's 'study of autobiographical memory' (33) 'anticipat[es] later discoveries' (2007: 31) about memory, and that he makes a 'contribution to memory studies' (24) with a novel that 'reads at times very much like a case study or a treatise, even, on the subject of personal remembrance' (2005: 22). Jonah Lehrer's Proust Was a Neuroscientist goes further, foregrounding the notion that 'We now know that Proust was right about memory' (2007: xi), and that he was one of numerous Modernist artists who 
'discovered truths about the human mind - real, tangible truths - that science is only now rediscovering' (2007: ix). By contrast, I will here attribute to Proust neither the intention to engage in a proto-scientific study of memory, nor the achievement of intuitive access to 'truths' about memory that have only recently been 'confirmed'. I do not claim that Proust 'knew' more about memory than, for example, William James or Paul Sollier, or that his project was an essentially scientific one in the guise of literature. However, the implications and effects of Proust's specifically literary engagement with memory are rich and complex, and I hope to show that recognising the mutual relevance of cognitive questions and the Search can be beneficial to scholars of Proust and of memory.

In the context of an approach encompassing cognitive-scientific perspectives, biographical considerations raise further questions related to the problematic notion of Proust as scientist. Proust was in close touch with the scientific and epistemological advances of his time: he was a passionate amateur psychologist from an early age (Zéphir, 1959: 13-31), and kept abreast of advances in the psychology of memory (Jackson, 1966: 12-13). Proust's interest in work by contemporary psychologists suggests that his textual treatment of memory need not be considered as divorced from the discourse and findings of his era's science. However, although Proust's engagement with contemporary science makes it likely that numerous currents of indirect influence and assimilation were at play in his fictional evocation of memory, any specific, direct influence is hard to prove. Even the relationship between Proust and Bergson, which is frequently held to be especially close, is problematic both personally and conceptually (see e.g. Delacour, 2001: 260-1), and may best be seen as a matter of 'adaptation' rather than 'imitation' (Nalbantian, 2003: 62). Comparisons of Proust's novel with scientific discourses contemporary to his writing cannot avoid complex and often 
irresolvable questions of 'influence' and 'intention', whereas an approach based on the findings and debates of recent cognitive science need posit no such connection.

Current cognitive science will be the basis for this inquiry, because its theories constitute the best understanding of memory currently available. My use of a scientific framework assumes neither that science makes absolute progress, nor that science is a unified entity from which findings can unproblematically be abstracted and re-applied. The cognitive sciences constitute (as the common plural suggests) a processual site of heterogeneous and often competing theories and traditions. Scientific 'truth' is at any point only the theory whose hypotheses and results best fit the current paradigm, in a Kuhnian sense (see Kuhn, 1996 [1962]). Especially in the study of the mind, however, new ground is constantly being broken, and indeed, some of the most exciting developments in the cognitive sciences occur when disparate disciplines (experimental psychology and philosophy of mind or artificial intelligence, for example) collaborate and create convergences. On the whole there is progress, not from falsity to truth, but either from demonstrably incorrect theories to more accurate ones, or from sketchy theories to more complete ones. As long as we bear these limitations in mind, it can be considered meaningful to analyse Proust's text in terms of its cognitive realism by engaging with late $20^{\text {th }}$-century and early $21^{\text {st }}$-century scientific results and debates.

Parts of the following analysis will also refer to certain facets of 'folk psychology': the concepts and convictions that make up people's everyday notions of human psychology, and more specifically, attributions of law-governed qualities to psychological events - for example, the causal connection of smell with memory in popular understanding. ${ }^{4}$ In folk psychology, as opposed to psychological science, there is relatively little difference between 
the early $20^{\text {th }}$ century and the early $21^{\text {st }}$, since folk-psychological notions are affected much less by current scientific trends than by enduring perceptions of experiential cause and effect (see e.g. Churchland, 1981: 74-6): the enduring nature of these principles is evidenced by their relatively unchanging expression in, for example, popular proverbs. The substantial effects of psychoanalysis on everyday conceptions and expressions of psychological phenomena in the early $20^{\text {th }}$ century may be seen as an exception to this stability, but many of its bequests to everyday language - repression, denial, the ego, and so on - may in fact be better seen as new terms for age-old concepts in the Platonic tradition. For my purposes here, no substantial difference will be assumed between the folk psychology of Proust's time and of our own.

Folk psychological concepts and explanations constitute a rich and detailed framework for understanding human psychology; many of its tenets are context-specific, although many are also generalized to account for, predict, or guide behaviour or beliefs (Ohreen, 2004: 114-15). Archival metaphors of memory and their associated predictions regarding memory function have, for example, long predominated in the folk psychology of memory (see e.g. Burton, 2008: 322). These can be seen as a specific instance of the broader conceptual metaphor 'the mind is a container' (Solomun, 2011: e.g. 25; see also Lakoff and Johnson, 2003: e.g. 148, 152), and serve the cognitive function of allowing memory to be understood in terms of our everyday interactions with physical objects. These archival metaphors generally work well enough to yield useful explanations, predictions, and strategies (otherwise they would not have lasted millennia). However, Jens Brockmeier (2010) shows how they are inadequate to account for many specific memory characteristics suggested by recent science. More broadly, although there are some areas in which folk psychology and psychological theory converge, Garth Fletcher (1995) points out that there are also many important differences between 
scientific and folk-psychological accounts of cognition. The scientific distinctions between episodic and semantic memory, or declarative and procedural memory, for example, 'cut[] up the dispositional cake' quite differently from distinctions in folk psychology between 'beliefs, attitudes, abilities, and the like' (1995: 35-6).

Finally, one might argue that conclusions about cognitive realism based on the workings of memory in the general population cannot be applied to the literary output of a genius someone who, by definition, differs from the psychological norm. There is evidence that creative writers exhibit especially high rates of severe and lifelong personality deviations (compared with the general population and with other types of creative individual), in particular with avoidant, obsessive-compulsive, and dependent characteristics, and certain emotional traits (Post, 1994). Proust is one of the writers whom Felix Post diagnoses with severe psychopathology. However, even in relatively severe cases, memory effects such as intrusive and repetitive flashbacks, and their emotional and behavioural consequences, can still be accounted for by general psychological principles (see e.g. Holmes and Hackmann (eds), 2004). More 'positive' features of creativity, such as problem-solving and the ability to perceive novel connections, may be linked to working-memory capacity, for example, but do not obviously implicate the aspects of memory function and experience discussed in this article. My working assumption is that Proust's memory and memory in the general population are likely to differ in degree rather than in kind. And, after all, the memories in the Search are of course fictional constructions, not (or as well as) specific psychological events experienced by the author of the novel.

With reference to specific areas of memory research, then, I will show that the madeleine episode is in part cognitively realistic (corresponding to cognitive realities, as documented by 
current science) and in part cognitively unrealistic (corresponding to common folkpsychological assumptions about cognition, or about the narration of cognition). Furthermore, defining the madeleine episode as an instance of involuntary memory, and more generally considering voluntary and involuntary memory as categorical opposites, as Proust usually presents them and we generally think of them, becomes problematic when we consider the textual details in light of scientific research. The episode's negotiation of the (apparent) boundaries between voluntary and involuntary memory is crucial to the novel's structure, not least because it complicates Proust's generally categorical distinction between the two. Returning to the text can thus deepen our understanding of both textual and cognitive phenomena, and how they interact.

\section{$\underline{\text { 2. Involuntary memory: introductory remarks }}$}

Involuntary memory was first systematically categorized by the psychologist Hermann Ebbinghaus, who in 1885 (1-2) distinguished between past 'psychische Zustände' (mental states) that are reproduced either 'willkürlich' or 'unwillkürlich' (voluntarily or involuntarily), the latter 'ohne jedes Zuthun des Willens, scheinbar von selbst' (without any involvement of the will, seemingly of their own accord). Other psychologists contemporary to Proust, such as Henri Bergson, William James, Frédéric Paulhan, and Théodule-Armand Ribot, studied the related phenomenon of 'affective memory', although without making strong claims about its voluntary or involuntary nature (see Jackson, 1966: 240-42). Proust acknowledged literary forebears in his evocation of (sense-cued) involuntary memory, including François-René de Chateaubriand, Gérard de Nerval, and Charles Baudelaire (VI 228-29), but heightened its significance as the mediator of a Modernist form of epiphany founded on intermittency. When the first volume of the Search was published in 1913, Proust gave an interview with Elie-Joseph Bois (reproduced in Kolb and Price, 1971: 215-20) in 
which he stated that 'mon œuvre est dominée par la distinction entre la mémoire involontaire et la mémoire volontaire' ('my work is dominated by the distinction between involuntary memory and voluntary memory'). ${ }^{5} \mathrm{He}$ cited the madeleine as the prime example.

Since then, involuntary memory as a phenomenon in itself (as distinct from the involuntary processes intrinsic to voluntary memory) has not been investigated nearly as thoroughly as its voluntary counterpart - partly because it is less susceptible to systematic laboratory study (see Ball, 2007). Many of the existing scientific papers on involuntary memory, such as John H. Mace’s (2004) article ‘Involuntary Autobiographical Memories Are Highly Dependent on Abstract Cuing: The Proustian View Is Incorrect', have engaged with its evocation by Proust, and the madeleine episode in particular. Yet most of these studies quote or paraphrase the text so selectively that crucial aspects of the experience evoked are omitted: in general, the focalizer's tasting of the tea and cake is followed by an ellipsis which makes the transition from tasting to remembering seem instantaneous (e.g. Baars et al., 2007; Berntsen, 2007; Chu and Downes, 2000a; Herz and Schooler, 2002). ${ }^{6}$ I will try to show that what occurs between the two is crucial to understanding and classifying this memory experience in terms of its cognitive realism (see also Jellinek, 2004).

The novel's opening pages describe the focalizer as lying in bed remembering his childhood, but able to remember only very specific, decontextualized times and places, primarily the events surrounding his bedtime (I 7-46). Anything else, the narrator declares, would in any case have been furnished only by 'voluntary memory, the memory of the intelligence', which is inherently limited: 'since the information it [voluntary memory] gives about the past preserves nothing of it, I would never have had any desire to think about the rest of Combray. It was all really quite dead for me' (I 46). The chance occurrence of being offered lime- 
flower tea and cake by his mother at the end of a tiring winter's day (I 44-48) is what allows the focalizer to remember more of his childhood than just 'the theatre and drama of my bedtime' (I 47), in a manner clearly presented in opposition to voluntary memory. After tasting a tea-soaked spoonful of madeleine, an initial experience of unidentified 'delicious pleasure' (I 47) has to be interrogated as to its origins, and threatens to fade with repeated tastes of the stimulus. ${ }^{7}$ The focalizer tries self-directed concentration and creative search, reconstructs the initial state and flavour, refreshes himself with distraction, ${ }^{8}$ then tries a further reconstruction; he senses a perceptual memory-image failing to emerge fully, fears it lost, tries ten times to reach it, resisting the laziness of letting it go, and at last suddenly grasps the memory of being given the cake by his aunt on Sunday mornings at Combray. This realization leads to remembrance of the house, the street, the town, and its inhabitants which in turn launches the narrative of events between ages about five and fourteen. The focalizer comes to understand the madeleine episode only near the end of the final volume, when more involuntary memories make him reflect on their qualities, consequences, and meaning.

\section{$\underline{\text { 3. The madeleine episode: cognitively realistic aspects }}$}

The madeleine episode's evocation of memory is cognitively realistic in four important ways: in the relationship between the focalizer's life-situation and the afternoon when he eats the madeleine, in his mental and occupational state when the madeleine is tasted, in the emotionality of odour- or flavour-cued memories, and in the longevity of such memories.

Involuntary memory can be understood as arising from the interaction of a current lifesituation and the immediate situation, the former exerting a priming effect on cues that appear in the latter - that is, making some stimuli more or less likely to be noticed and to effectively 
trigger memory experiences (Berntsen, 2007: 41). The focalizer's current life-situation when the madeleine episode occurs is clearly characterized as one of repeated reflection on the years of his childhood, but accessing only memories of bedtime routines: 'this sort of luminous panel, cut out from among indistinct shadows' (I 46). All other memories from this period may be assumed to be very weakly activated during reminiscence (Mace, 2005): too weakly to be experienced as memories at the time, but strongly enough to increase their chances of subsequent retrieval, through associative priming. This means that, for at least a few days after reminiscence (Mace, 2005: 882-83), cues such as the cake and tea, which seem to occur and operate randomly, are in fact primed to be noticed and to induce memories of their original occurrence. This happens, as the text has it, through 'the attraction of an identical moment' (I 49): that is, through the workings of associative memory. A cognitive connection is established by a single factor common to both a present and a past event, and to both the immediate situation and the content of one of the weakly activated memories.

There is also evidence that the majority of involuntary memories occur in non-focussed, or 'diffuse', states of attention, and when people are alone, and/or engaged in routine or automatic tasks which do not require full attention (e.g. Berntsen, 1998). This pattern may be due to enhanced cue-processing in such states, or because an inhibitory mechanism preventing such memories arising during focussed states is relaxed. The focalizer's state prior to eating is non-focussed, and the act of doing so is automatic: he raises the spoon to his lips 'mechanically' (I 47), depressed by the day that is past and the one to come, but not dwelling on the details of either. His life situation, then, is one of dissatisfaction with the present and preoccupation with the past, a combination sharpened by the immediate situation: his temporary coldness, tiredness, and inattentiveness. The 'chance' appearance of the madeleine is therefore in fact highly primed to be noticed and to act as an effective memory cue - 
primed by the life situation (dissatisfaction and reminiscence) and by a non-focussed state and mechanical task.

A key characteristic of the madeleine episode consists in the combination of the sensory (primarily olfactory) cue and its strong emotional effect. Here too the evocation of cognition is cognitively realistic. The lateral olfactory stria (which connects the olfactory bulb to other brain areas $)^{9}$ has a direct anatomical connection with the amygdala-hippocampus complex, the 'neural substrate of emotional memory' (Herz and Schooler, 2002: 22). Thus olfactory information has direct access to emotion- and memory-related neural areas, which helps explain the potency of odours and flavours in triggering emotionally potent memories. But although 'Proustian' memory is usually described as emotionally charged, the text itself presents the memory-emotion connection rather differently. The most obvious focus of empirical studies on emotion, memory, and olfaction is the emotional quality of the original event-stimulus or of the odour-cued memories. In the madeleine episode, however, the memory initially triggered by the tea-soaked cake is not essentially imbued with emotions the central event remembered, of being given tea and cake on Sunday mornings, is quite ordinary, although events later associated with it by temporal contiguity are more emotionally laden. Furthermore, what causes the pleasure is not the remembering (this has not yet occurred), but the experience of tasting again the once-familiar flavour. Recognition occurs long before remembering does, as first signalled by the focalizer instinctively dipping a piece of madeleine into his tea, just as his aunt used to do. ${ }^{10}$ The 'delicious pleasure' and the 'powerful joy' (I 47) are emotions in the present, induced by the experience of familiarity even before retrieving the memories associated with it. 
The neurological connection between olfaction and emotion, with only two synapses separating the olfactory nerve from the amygdala (Herz and Engen, 1996: 300) - or, more precisely, the lateral olfactory stria from the cortico-medial region of the amygdala -, entails 'a special physiological preparedness for odors to acquire emotional significance beyond that of the other senses' (ibid.: 309). Furthermore, olfactory and gustatory neural messages converge in orbitofrontal cortex, which has reciprocal informational links with the amygdala, and plays an important role in mediating hedonic experience and sensory reward/punishment associations (Kringelbach, 2005). The focalizer's mood-change is thus explicable with reference to the 'strong signal [. . .] sent from the olfactory system, reinforced by the taste system, to the reward center in the orbitofrontal cortex' (Utermohlen, 2002: 102). Explicit memory retrieval is therefore not necessary for the odour to induce emotion.

An additional factor, the 'exposure effect', may also be at work here, however. The exposure effect is the pleasure we find in and preferences we form for familiarity; this welldocumented phenomenon can be explained with recourse to the positive emotion that results from processing fluency (Bornstein, 1989). Studies on the exposure effect with odour and flavour have in general confirmed its existence, especially with initially unfamiliar foods (as tea-soaked madeleine will have been to the young boy) and especially with delay between exposure and rating (Bornstein, 1989: 278; see also Sulmont et al., 2002). Furthermore, olfactory perception and preference are determined by past experience more than other sensory modalities (Stevenson and Boakes, 2003; see also Shepherd-Barr and Shepherd, 1998: 53-54). This fact, combined with the positive emotional effects of familiarity, may heighten the neuroanatomically determined emotional effects of the odour/flavour experience. Thus we can account for the focalizer's extreme positive reaction in a more nuanced way than previously. Even before the odour and flavour are explicitly identified or 
their associated memories retrieved, positive emotion is likely to be induced by a combination of neurological determinants and the exposure effect.

The strong neurological link between olfaction, emotion, and memory also means that olfactory cues are strikingly effective at retrieving even very old memories. Studies suggest that although accuracy of short-term recognition is lower for odours than for visual stimuli, in long-term memory much less olfactory than visual information is lost (e.g. Engen and Ross, 1973). If olfactory elements of experiences are especially enduring, other elements may have decayed too much to serve as retrieval cues, but still be accessible enough to be retrieved when cued by olfactory aspects of the same experience. Precisely this is evoked in the madeleine episode:

of these recollections abandoned so long outside my memory, nothing survived, everything had come apart; the forms - and the form, too, of the little shell made of cake, so fatly sensual within its severe and pious pleating - had been destroyed, or, still half asleep, had lost the force of expansion that would have allowed them to rejoin my consciousness. But, when nothing subsists of an old past, after the death of people, after the destruction of things, alone, frailer but more enduring [French 'vivace'], more immaterial, more persistent, more faithful, smell and taste still remain for a long time, like souls, remembering, waiting, hoping, on the ruin of all the rest, bearing without giving way, on their almost impalpable droplet, the immense edifice of memory. (I 49-50) 
Here the madeleine's appearance has lost the capacity to induce cognitive 'expansion' - in neurological terms, the activation of synaptic connections strengthened by previous encounters with the stimulus - but its odour and flavour retain this capability. This may partly be a function of the specific case: the narrator remarks just prior to these lines (I 49) how often he had since seen madeleines, without ever smelling or tasting them, so that their appearance had become dissociated from the memory by repeated exposure leading to cue overload (see Watkins, 1990: 331-32), where their odour and flavour had not. However, these lines also underscore the nature of odour and flavour as more 'frail' and insubstantial - it is, for instance, notoriously difficult to verbalize the complex 'odour images' created by activity within the olfactory bulb (Shepherd, 2006: 318) - but conversely more 'enduring', 'persistent', and 'faithful' than vision (or hearing). Empirical data speak to this characterization: one laboratory study (Herz and Cupchik, 1992) found that odour-cued memories are highly emotional (60.4\% of participants' memories were rated thus), vivid (50.9\% were rated 'very clear'), specific, rare, and relatively old (25.6\% of those dated to periods earlier than the past 12 months were from the 'early childhood' period).

\section{The madeleine episode and folk psychology}

Memories cued by olfactory sensations therefore seem privileged in several ways. There is, however, also evidence that the vividness and specificity (and, by implication, accuracy) of odour-cued memories may be exaggerated because of their emotional quality, which creates a greater sense of being 'brought back' by the memories, leading them to be reported as more vivid and specific than they actually are (e.g. Herz and Schooler, 2002). It has also been suggested that the greater age of odour-cued memories may be an illusion created by their greater inaccessibility (Rubin et al., 1984); but other data, based on older participants' memories, demonstrate a significant shift back in the 'memory bump' for odour-cued as 
opposed to verbally cued memories (Chu and Downes, 2000b). So the 'fidelity' of such memories may be an illusion, but the 'persistence' (longevity) and 'endurance' (including an emotional power to 'bring back (to life)', in the adjective 'vivace') seem less likely to be. Proust seems to tap into cognitive realities (as conceived by current science) regarding the longevity and power of odour-cued memory, and, as further explored below, perhaps rather into our assumptions about cognition regarding the vividness and specificity of odour-cued memories. ${ }^{11}$ This latter aspect - the correspondence to assumptions about cognition rather than to cognitive realities - is one possible cognitively unrealistic feature of the episode.

The episode taps into 'folk psychology' rather than what seem to be the cognitive realities in a second respect: the relative frequencies of sensory and other cues in eliciting involuntary memories. Recent evidence suggests that, contrary to popular belief, involuntary memories are more likely to be triggered by abstract or verbal cues than by sensory or state (physiological or mood) cues. Mace (2004) found that $68 \%$ of participants' involuntarymemory experiences were triggered by verbal cues, with only $30 \%$ due to sensory cues and $2 \%$ to state cues. Of the sense-cued memories, only a small number - $3 \%$ of the total memories - were induced by odours or flavours. Here too, the memories' emotional quality may be responsible for misconceptions: Mace suggests that this, and a stronger sense of being 'brought back', makes sense-cued involuntary-memory experiences more salient and hence memorable than those triggered by abstract/verbal cues, thus making them seem a more common occurrence than they really are. Sense-cued memories are also, Mace suggests, likely to be less congruent with current cognitive activity, again making them more salient and less likely to be confused with a voluntary memory, as may occur if the cue is a thought or the reading of a word (2004: 898-99). 


\section{Folk psychology and narrative convention}

A further consideration important to understanding Proust's madeleine episode is the specificity and extent of the retrieved memories. These constitute arguably the episode's single greatest deviation from cognitive realism in the evocation of memory. The quantity of details that, in the following section of the novel, are narrated - implicitly as being recalled about location, people, and especially conversations goes beyond everyday inflations of the amount of detail provided by odour/flavour-cued memories. The imperfect tense used throughout much of 'Combray II' invites the interpretation that the dialogue, for instance, is not being recalled and recorded verbatim (an implausible feat of memory for a normal human), but is being reconstructed and paraphrased from numerous similar specific episodes. This would correspond more accurately to the psychological facts than does the widespread folk concept of memory as a static storage capacity; memory is more 'reconstruction' than 'reproduction' (Bartlett, 1932; Schacter and Addis, 2007). Nonetheless, there are many instances of dialogue tagged by the simple past ('dit-il', 'demandai-je'; 'he said', 'I asked', etc.). Furthermore, the structural conceit which makes the madeleine the cognitive trigger for remembrance of all that follows compels us to read the memories not as reconstructed by 'intellectual', or voluntary, memory, but as yielded spontaneously (after the initial effort) by involuntary memory. Similarly, although one sentence presents the effort (to remember) as a creative, constructive act ('Seek? Not only that: create', I 48), it is contradicted both by all the surrounding terminology of effortful search and by the final transition to sudden recollection ('And suddenly the memory appeared', I 49). Thus our understanding of what the focalizer remembers is subject to an irresolvable tension: either the memories are themselves cognitively unrealistic (as highly detailed spontaneous recollections), or they contradict (as retrospective reconstructions) much of the textual evidence of searching and 
finding, and the madeleine episode's wider import as a trigger of involuntary memories that instantaneously bring back a whole era. ${ }^{12}$

The double internal focalization of the Search foregrounds the questions of who narrates, and therefore who remembers; the novel's memory-based structure thus inevitably entails a conflict between the textual scope and detail, and the evocation of remembering as a cognitive activity. And given the further aim to contrast voluntary and involuntary memory, the former's capacities have to be denigrated and the latter's exaggerated, to make the novel possible. As a novel, this works rather well, since the less attention is drawn to incompleteness or informational gaps, the more coherently, reassuringly familiar a narrative seems. Cognition and consciousness consist of fundamentally multiple, parallel, non-unified processes, and Daniel Dennett's (1991) metaphor of 'multiple drafts' is in this sense more accurate than the folk-psychological commonplace of a single 'stream of consciousness' (James, 1891: I 360). Nonetheless, the habit of narrativizing - making retrospectively meaningful, linear, and singular narratives out of one's own experiences - is ubiquitous, whether the narratives are unarticulated or made public: 'An important property of the life story, both linguistically and psychologically, is that is must be coherent. Its coherence is not a property of the life, but rather an achievement of the speaker in constructing the story' (Linde, 1987: 346). Literary narratives that do this therefore have an instinctive appeal, which increases the more proficiently they balance referential detail with efficient meaningfulness. Important things should no more be missing than trivial things should be included, so that the effect of reality itself, with all its potentially unsettling aspects, is subordinated to the 'effet de réel', the 'reality effect' (Barthes, 1986). This is what the sections following the madeleine's consumption achieve, deflecting the question of how much could realistically be remembered through the ease with which familiar cognitive narratives are set in motion. 
Coherence as a property of memory reports rather than of the memories themselves is a demand convergent with that of literary form. The description of 'all of this which is assuming form and substance' (I 50) after eating the madeleine seems, indeed, 'better suited to the content of a self-narrative than the typical fragment of content associated with involuntary autobiographical memories' (Ball et al., 2007: 116). This observation reinforces the conclusion that in the memories elicited - as distinct from their cueing and retrieval - the relationship between narrative and psychological factors is especially complex: the narrative of 'remembered' events taps into our expectations about what good narratives should do, but these in turn may well derive from our cognitive habits of narrativization. We might therefore conclude that the wealth of coherently linear 'recalled' events is cognitively unrealistic because it belies the multiple parallelisms of cognitive activity, but feels plausible because it corresponds to our folk-psychological understanding of cognition, based on our habits of creating coherent cognitive narratives.

\section{The madeleine episode as voluntary memory}

We have now considered the ways in which the madeleine episode is cognitively realistic in evoking an involuntary memory, and the ways in which it can be considered unrealistic in corresponding to common habits and expectations rather than to what current science suggests are the cognitive realities. Lastly, we will consider some ways in which the episode is cognitively realistic, but not as involuntary memory - and indeed how this category itself may need reconsidering. The factors of specificity in initial remembering, and time and effort taken to remember, are key here. Martin Conway has proposed that the preferred level of access to autobiographical memory is the general event (e.g. a holiday, or a habitual weekend excursion), rather than the specific event (e.g. going to a particular museum, a single time) or 
the life period (e.g. the childhood years when one lived in the country) (Conway, 1996: 6970; see also Conway, 2005: 612). This can be considered the 'basic level' of autobiographical memory (Rosch, 1977): at this level of specificity, memories yield the proportionally greatest amount of information for the effort required to access them. And this is the level of specificity at which the memories elicited by the madeleine initially emerge. The focalizer realizes:

That taste was the taste of the little piece of madeleine which on Sunday mornings at Combray (because that day I did not go out before it was time for Mass), when I went to say good morning to her in her bedroom, my Aunt Léonie would give me after dipping it in her infusion of tea or lime-blossom. (I 49)

The combination of the imperfect tense (in the French 'je ne sortais pas', 'j'allais', etc.) and the explicit temporal marker of repetition ('on Sunday mornings') clearly denotes this as a general event - a repeated event, or a sequence of related events - which is just accessible enough through general autobiographical knowledge structures that it can, after some effort, be retrieved, and just specific enough to trigger the numerous specific-event memories that constitute the following text. Interestingly, though, the general-event priority posited by Conway applies to voluntary rather than to involuntary autobiographical memory; substantial evidence suggests that amongst involuntary memories, where a hierarchical search process is not required, there is a higher proportion of specific episodes relative to general events (Berntsen, 1998 and 2007). This is a first clue that the madeleine episode involves something other than self-evidently involuntary memory. 
The madeleine episode also demonstrates, in exaggerated form, cognitive realism in a second area that challenges the memory's definition as involuntary: that of time-scale and effort. The episode is structured by the striking slowness of autobiographical memory retrieval compared to retrieval of other forms of knowledge, such as word meanings (which tends to take a few hundred milliseconds) and autobiographical factual knowledge (around 1,200 milliseconds) (Conway, 2005: 620). And memory experiences that require voluntary, 'generative' retrieval are significantly slower than involuntary memories that are triggered spontaneously without efforts of cue elaboration (Ball et al., 2007: 121-23). A recent study (Schlagman and Kvavilashvili, 2008) using both laboratory and diary methods to compare retrieval times found consistently longer mean retrieval times for voluntary memory (around 10 seconds) than for involuntary memory (around 5 seconds). Retrieval may be all the more effortful and time-consuming if it involves first identifying an odour/flavour cue; empirical research has suggested that odours frequently elicit 'tip-of-the-nose' failures of identification, despite strong feelings of familiarity. Lawless and Engen (1977), for instance, found that familiarity judgements took an average of around 7 seconds, retrieval of associations around 9 seconds, and naming around 12 seconds. I do not wish to suggest that this passage of Proust's should be expected to conform to (or diverge from) behavioural studies at the level of seconds or milliseconds. However, the temporal guidelines provided here by scientific findings are helpful in broaching the significant question of this memory's status as voluntary or involuntary.

In the madeleine episode, retrieval of associations only minimally precedes, or occurs simultaneously with, identification: 'And suddenly the memory appeared. That taste was the taste of the little piece of madeleine' (I 49). But overall, the process of memory retrieval through odour identification is a long-drawn-out one. It is hard to tell precisely how much 
time elapses between first tasting the madeleine and retrieving the associated memories: descriptive detail is extensive at each stage, and deictic temporal indicators denote the passage of time through references to contiguous sections of experience rather than to the absolute intervals of clock time. Words and phrases such as 'soon', 'immediately', 'at the very instant when', 'As soon as I had recognized the taste', and 'Ten times I must begin again' (I 47-50) create a continuous sequence whose intervals are evoked only subjectively, and whose frequent transitions between imperfect, pluperfect, present, and future tenses create a network of cause and effect that expresses the significance and complexity of the event without stating its duration explicitly. Nonetheless, the process clearly lasts for at least many seconds, and probably many minutes. Although it is later clearly characterized as involuntary, remembering here is much more like voluntary retrieval in terms of the time and iterative effort involved. $^{13}$

The definition of involuntary memory is that it (the memory itself, not just a preliminary sensation or emotion) is triggered unintentionally, whether by 'internal' (mental, emotional, or state-related) or 'external' (sensory or verbal) stimuli. A common misconception about the madeleine episode is that the cued memory is 'involuntary' in the sense of requiring no deliberate effort to be accessed. ${ }^{14}$ On the contrary, as has been pointed out by some memory researchers and literary critics (e.g. Ball et al., 2007: 116; Delacour, 2001: 262; Ender, 2005: 32; Shepherd-Barr and Shepherd, 1998: 45-46, 54-5), considerable effort is involved in rendering the memory identifiable and explicit. The focalizer's questioning of his great pleasure leads to identification of what is being sought as, specifically, 'le souvenir'. After this partial definition, a search specifically for that memory takes place, consisting of all the stages described above (p. 00). Rather than an involuntary memory occurring in isolation, or prompting subsequent elaboration by voluntary generative retrieval, the text clearly evokes 
the process of generative retrieval, or cue elaboration, in which a given cue is cognitively elaborated until episodic memories emerge, often in vivid perceptual-imaginative form. ${ }^{15}$ This culminates in a memory which feels involuntary because of its sensory cue, sudden (though delayed) emergence, and vivid and comprehensive details, but which in experimental terms would certainly be defined as the end-point of cue elaboration in voluntary memory. This general-event memory in turn yields a great number of specific-event memories through a process of memory chaining (Mace, 2007; see also Shepherd-Barr and Shepherd, 1998: 55). All this seems to undermine the entire voluntary/involuntary distinction of which Proust made so much, perhaps - as will be discussed in conclusion - because the neat theoretical distinction could not be upheld in the narrative practice of extended psychological evocation.

Why, then, has the madeleine episode become so famous an example of involuntary memory? The novel contains plenty of other striking instances of sense-cued involuntary memory, notably the five cases in Finding Time Again (VI 174-96). There, although deliberate effort may be involved in seeking out the 'meaning' of what is remembered, the memories themselves in most cases come quickly and unbidden. Why should the madeleine episode have eclipsed these other, rather better, examples? Elizabeth Jackson argues that it is the most beautiful memory of its kind, and the most tension-filled and directly joyful (Jackson, 1966: 185-86, 235-36). The madeleine episode is also the only instance of ‘involuntary memory' that yields a substantial narrative of the past (Terdiman, 1993: 227). Or perhaps the key is its use of an olfactory/gustatory cue to memory: given the privileged neurological position of the olfactory system, the other examples may reasonably seem less potent. Indeed, in Finding Time Again, the memories induced by sensations other than odour/flavour or taste are discussed as examples of imaginative 'tasting' (French 'goûter', translated as 'enjoy', VI 179-80), presenting this as a fundamental quality of 'involuntary 
memory' and its metaphysical consequences. Any and all of these factors may contribute to the madeleine's preferential treatment in cultural history over the novel's other, more clearly involuntary memories.

The madeleine episode seems, then, a powerful evocation of memory in spite not because of its intra- and extratextual presentation in opposition to voluntary memory; the voluntary/involuntary distinction seems almost a red herring. Jackson suggests that the involuntary quality of 'affective memory' or 'unconscious memory' was an afterthought in the evolution of involuntary memory in Proust's thinking: originally, she argues, the 'affective' - emotional and sensory - factors were key, and the involuntary element may later have been emphasized to increase the contingency and hence drama (1966: 15). Richard Terdiman argues that the voluntary/involuntary distinction which forms the novel's superstructure and its culmination is central to the unsuccessful attempt to reduce multivalence to singularity and contingency to the absolute by making memory solve all the questions and problems the novel poses. This requires that the positive emotional effects of the involuntary memories that counter the deadening effects of habit be exaggerated, along with the freedom of involuntary memory from the suspect distortions of 'conscious' subjectivity that shape voluntary memory (1993: 155, 181-83, 209-12, 227, 235).

\section{Voluntary and involuntary memory in the Search and beyond}

Although in the Search itself Proust does not explicitly use the term involuntary memory ('la mémoire involontaire') to denote experiences like that of the madeleine, the voluntary/involuntary opposition is nonetheless conceptually significant in the novel. The notion of the involuntary is frequently paraphrased, as for instance when the episodes of sense-cued remembering are discussed in Finding Time Again: 
their primary character was that I was not free to choose them, that they were given to me just as they were. And I sensed that this was the mark of their authenticity. I had not been looking for the two uneven paving-stones in the courtyard where I stumbled. But the very fortuity, the inevitability of the manner in which the sensation was encountered, controlled the authenticity of the past that it resuscitated, the images it let loose, since we feel it striving towards the light, we feel the joy of the real, found again. (VI 187)

The 'authenticity' of such memories, and the 'joy of the real, found again' which they induce, derive from their being unsusceptible to choice, to being sought out, and instead being both 'fortuitous' (will power not causing them) and 'inevitable' (will power unable to avoid them). These facets are emphasized in the madeleine episode by remarks on the taking of tea being 'contrary to my habit' and the acceptance of it occurring 'I do not know why' (I 47); these interjections stress that there was no 'deliberate' seeking-out of the stimulus. As we have seen, though, the involvement of priming effects means that the 'deliberate' and the 'chance' are less distinct than Proust would have them be.

Distinctions contributing to the fundamental claim to authenticity through unwilled chance are woven through the novel: the 'conscious' is repeatedly opposed to the 'unconscious', 'intelligence' to 'sensation' or 'impression'. These oppositions can be seen as reflecting the cultural importance of the unconscious in early $20^{\text {th }}$-century Europe, as the artistic avant garde responded to Freud's expansion and popularizing of pre-existing theories of the unconscious, and psychoanalytic terminology became part of everyday discourse. All these 
oppositions are bound up with that only partially articulated voluntary/involuntary dichotomy, ${ }^{16}$ and all express an essentially dualist conception of selfhood and subjectivity.

The value judgements associated with this dualism in the Search are not simplistic: the passage partially quoted above also intimates that the 'unconscious' pole, the 'sensation', is not itself the end-point, but the means to a 'new truth', or a 'precious image', conveyed through the 'signs' or 'hieroglyphics' of the sensory stimuli; this preserves a valid role for intelligence and intellectual knowledge (VI 186-87; see also 207). Ender (2003: 28) argues that the madeleine episode represents a shift in the rememberer's conception of memory, from a privileging of mind over body to a recognition of the latter's importance. But this of course does not dissolve dualism: the acknowledgement that there are two poles perhaps even reinforces their opposed nature.

Such oppositions, however subtly structured, presuppose that there is a fundamental difference between doing something voluntarily and doing it involuntarily, and between intellect and sensation (a sensation arising and experienced involuntarily, its intellectual interpretation then willed). In Proust's discourse, these oppositions are inseparable from the oppositions between a controlling 'consciousness' and the otherwise uncontrolled - and more authentic - workings of the 'unconscious', and between a 'mind' and the 'matter' of brain and body. Neither of these related oppositional structures is supported by psychological or physiological evidence. ${ }^{17}$ Work in psychology has suggested, for example, that factors such as priority, consistency, and exclusivity in the relation between a thought and an action alter the degree to which a sense of control over even forced actions is experienced (Wegner and Wheatley, 1999). Proprioceptive and kinaesthetic feedback also play an important role (Nahmias (2005: 773-74), in a critique of Wegner). We may therefore conceive of the 
experience of agency as constituted by a complex set of factors which cannot be neatly divided into voluntary and involuntary. Experiments in neuroscience, meanwhile, have demonstrated that neural activity (in specific areas of fronotopolar and parietal cortices) encodes the outcome of a decision up to ten seconds before awareness of the outcome (Soon et al., 2008), further blurring the voluntary/involuntary distinction and sharpening the question of what role, if any, consciousness plays in voluntary action.

Ultimately, we may conclude that drawing a categorical distinction between voluntary and involuntary actions (or decisions, or memory retrievals) requires an invocation of what Dennett (1991) calls the Cartesian Theatre: the place in the brain where everything comes together 'in consciousness', and where the privileged audience of one watches the performance. The Cartesian Theatre entails a dualist boundary between the conscious and the unconscious - and equally, I argue, between the voluntary and the involuntary - that can be upheld 'all the way in', to the micro-level of neural events. Whether or not this is explicitly envisaged in the stronger terms of an inner homunculus as an 'I' who acts (decides, retrieves), the same basic, potentially misleading structure is at work (see also Blackmore, 2005: e.g. 128-31). Any given action, decision, or memory retrieval is perhaps better thought of as beginning when it does because neurological, physiological, and environmental factors combine at a given moment to make the process start.

Thus the memory categories 'voluntary' and 'involuntary' become as questionable as are those of 'conscious' and 'unconscious'. George Mandler (2007) points out that we have no theory of consciousness which could tell us how 'voluntary' thought comes about - and empirical evidence to refute its existence - and suggests an alternative to the voluntary/involuntary and conscious/unconscious pairings: 'expected' and 'unexpected', 
envisaged as a continuum rather than an oppositional distinction. The more expected and the more unexpected might denote, respectively, lesser or greater deviation from current cognitive activity, physiological and mood states, and action goals. This would complement a perspective outlined above (p. 00): one of Mace's possible explanations of people's tendency to over-estimate the proportion of sense-cued involuntary memories was that these may present a more salient contrast with current cognitive activity, and hence seem more obviously - and memorably - 'involuntary' (Mace, 2004). In other words, memories seem involuntary because they come as a surprise, are unexpected. Whether the immanent cue is a flavour, an emotion, a mood, a physical state or action, a word, or a thought, the ensuing process is not categorically different; a 'thought' should arguably not have a status entirely different from that of other potential cues, because it is no more 'intended' by the nonexistent Cartesian Theatre's audience of one (Dennett, 1991).

Some brain-imaging data provide evidence of a neuroanatomical dissociation between voluntary and involuntary recall, but a number of these studies are based on problematic assumptions such as the equation of recognition with recall, and there is also evidence to the contrary: for example, activation of the amygdala, hippocampus, and dorsolateral prefrontal cortex regardless of the 'intentional' or 'incidental' nature of retrieval (for a review see Hall, 2007). Discrepant results of this sort indicate that more investigation is needed of the neural correlates of memory experiences associated with different cues, retrieval modes, memory/recall characteristics, and post-retrieval monitoring/evaluation, not least in boundary cases, to establish whether neural activation patterns denote a qualitative distinction or a continuum. In this sense, while exploration of the varying conditions, qualities, and effects of variously cued memories is invaluable, it may be inaccurate, if convenient, to create a sharp dividing line between 'voluntary' and 'involuntary'. Proust does this explicitly, for example 
in the interview quoted above, and implicitly through paraphrase and antithesis in the Search itself. But it is telling that his key instantiation of 'involuntary memory', the one which introduces the theme and to which his narrator refers most often in the generalizing conclusions of the final volume, resists this classification in a manner so striking that, if we do want to retain the opposing categories, it falls into the wrong one.

\section{Conclusion: The madeleine, memory, and readers' responses}

Literature's most famous example of involuntary memory turns out not to be involuntary after all; but as a detailed evocation of generative retrieval cued by an olfactory/gustatory sensation, it is cognitively realistic in numerous aspects, and where it is unrealistic, our narrativizing mental habits and our expectations regarding cognition and narrative coherence mean that we probably accept it anyway. The episode performs the unlikely feat of never being cognitively realistic in ways likely to forcefully contradict our expectations about cognition. Without exception, the realistic features - priming through reminiscence, statedependent retrieval, the emotionality and longevity of odour-/flavour-cued memories, the effortful search sometimes required to identify odours and flavours and to retrieve the memories associated with them - can be aligned with common facets of folk psychology. We have, for example, certain 'common-sense' expectations about memory which can be connected to the archival metaphor of memory as static storage mentioned on p. 00 above: these include the notion that remembering one thing makes related memories more likely because stored items 'nearby' are more likely to be easily found - and that memories come easier when one's mind is at rest - because other activity is not interfering with the 'search' process. Where there are unrealistic features, they again converge with common assumptions about memory (and narrative) - that is, in the vividness and specificity of sense-cued memories (and of narrative), and in the frequency of memories cued thus as opposed to by 
abstract cues. Where realities and expectations converge, Proust evokes cognition accordingly; where they diverge, he follows folk psychology rather than cognitive reality. This means that we nowhere find cognitive realism contradicting expectations, entailing the ambivalent response - both compelled and unsettled - that seems to occur when, for example, Kafka evokes vision counter to our pictorialist assumptions (Troscianko, 2010) or when Flaubert evokes memory counter to our understanding of it as static storage (Troscianko, forthcoming 2012). Even the border case of vacillation between evoking the effort to remember as searching/finding or creating leaves us free to choose the interpretation we prefer, rather than imposing a counterintuitive one upon us.

Nonetheless, the result of all this is cognitively realistic in a highly counterintuitive manner: the suggestion that there is no categorical distinction between voluntary and involuntary memory. Because the madeleine episode defies the characterizations of it later in the novel and elsewhere, by making 'involuntary' memory the stuff of protracted and effortful search, it becomes ultimately more cognitively realistic than Proust himself, intent on rescuing past reality from present distortion and authentic memory from the strictures of consciousness or intelligence, may have wished to acknowledge. The major cognitively unrealistic feature the amount of detail retrieved - is a concession to expectations of completeness born of mental habits and both fostered and satisfied by narrative conventions. However, even this can be redefined as a form of cognitive realism if we reinterpret the episode's one explicit distinction between creating and seeking/finding (I 48) as in fact an acknowledgement that they are always combined (the phrase is, after all, 'Seek? Not only that: create', I 48). While remembering has some search-like qualities and a neural basis in 'long-term potentiation' of synaptic connections, it is always creative too: every memory retrieval is a reconstruction, never recreating exactly the same memory twice, and profoundly dependent on many aspects 
of the present context (Brockmeier, 2010; Conway, 2005). The madeleine episode is cognitively realistic despite the narrative's (and Proust's) later gloss on it as involuntary, and despite the shift from extended effort to instantaneous 'total recall'. Yet this fact seems very easy to ignore, judging from the episode's reception by critics, readers, and memory researchers over the decades.

The most remarkable achievement of the madeleine episode is in allowing readers to read in it confirmation of their assumptions about memory - about flavour-cued memories being involuntary, instantaneous, and rich in accurate detail; about remembering being only a search of pre-existing contents rather than involving goal-orientated (re)creation - whilst simultaneously contradicting these assumptions. This effect is especially significant in a novel which defied aesthetic conventions and readers' expectations regarding many features, including chronology, descriptive style, and syntax. In the area of memory, by contrast, the text does not confront the reader forcefully with what is counterintuitive or unexpected, but creates a more subtle challenge to expectations. Empirical research on readers unfamiliar with the novel could help to establish how far this effect would hold if the episode were read in isolation, without the later interpretive passages (and others' reformulations of these) affecting their responses.

In any case, the paradox is a striking, and psychologically telling, one: cognitive realism is in some ways less powerful a force than are our assumptions about cognition, yet the two can coexist quite happily within the same famous section of narrative. Here they contradict each other yet may well manage to reap the rewards of both at once: the sense of pleasing familiarity that may result from assumptions confirmed, and the sense of compelling ease more likely to result when cognitive realities are directly tapped into. This allows the episode 
to 'smuggle through' an idea that might otherwise be highly unsettling: that there is less difference than we think between doing something voluntarily and doing it involuntarily. A startling reality is there amongst all the compelling and reassuring features - but they allow us to ignore it if we wish. Maybe this is why the madeleine has become one of the world's most famously evocative flavours.

\section{Acknowledgements}

I thank Sue Blackmore, David Mossop, John Sutton, and three anonymous reviewers for their generous and helpful comments on earlier versions of this article.

\section{Funding}

This research received no specific grant from any funding agency in the public, commercial, or not-for-profit sectors.

\section{Notes}

1 Involuntary memories can also be 'semantic' (e.g. of words/tunes) but I use the term ‘involuntary memory' to designate 'involuntary autobiographical memory' (of events/experiences in one's past).

2 The term 'focalizer' (deriving from Genette, 1980: 189-211) denotes the experiencer, as opposed to the narrator, of the fictional events. In the Search, structured by 'double internal focalisation' (Rogers, 1965: 121-23), the 'I' shifts between the naïvely experiencing and the retrospective comprehending focalizers, who fuse in the final volume, when the latter becomes his own narrator.

3 Epstein (2004) also offers a complex account of the emergence of Proust's 'theory of aesthetic perception'. 
${ }^{4}$ The prevalence of these associations between smell and vivid, emotional memories is evidenced by testimony collected in 1935 , before the Search had become a ubiquitous point of reference (or source of bias) in this area (Laird, 1935). Donald Laird reports how respondents to an inquiry about odour-cued memories provided rich documentation of how, for example, 'odors have been prodding my memory possibly throughout my life' (127) or, 'having long since come to the conclusion that in my particular case the sense of smell is an especially effective memory-stimulus, I have accepted it and ceased to note down particular cases' (127). It thus seems legitimate to claim (pace Chu and Downes, 2002: 511) that Proust taps into, rather than creating, such beliefs.

${ }^{5}$ In the novel itself, the term 'voluntary memory' occurs three times, its opposite only once, and merely in passing (VI 5).

${ }^{6}$ This strategy is not limited to scientific commentators: see e.g. Lennon (2007).

${ }^{7}$ On the neurological mechanisms of sensory adaptation, see Shepherd-Barr and Shepherd (1998: 50).

${ }^{8}$ See Mandler (1994) on the possible benefits of this.

9 The olfactory system processes odours and flavours either via orthonasal perception (breathing in through the nose) or via retronasal perception (volatile molecules from food in the mouth being pumped up from the back of the oral cavity when breathing out through the nose). Eating the madeleine activates both olfactory routes, plus the gustatory system (via tongue receptors for sweetness). The general emphasis, in experimental studies referring to Proust, on odours alone is potentially problematic, since beyond their common connection to the amygdala-hippocampus complex, flavour-processing involves multiple sensory modalities, motor systems, and generally far more widespread neural activation than odourprocessing (Shepherd, 2006: 317). 
${ }^{10}$ See Shepherd-Barr and Shepherd (1998: 49) on how this strengthens the madeleine's aroma essences.

${ }^{11}$ See Note 4.

${ }^{12}$ On Proust's 'pseudo-iterative', see Genette (1980: Ch. 3).

13 Shepherd-Barr and Shepherd (1998: 55) suggest neuroanatomical reasons for the focalizer's highly motivated state.

${ }^{14}$ See p. 00 above for scientific commentators who overlook the time and effort involved in the memory retrieval; and in literary studies, for example, the introductory essay by Jordan (2001: 112-13) and the in-depth analysis by Zéphir (1959).

15 The specification 'visual memory' indicates the perceptual-imaginative nature of the memory sought; see Conway and Pleydell-Pearce (2000: 263) on imagery and memory.

${ }^{16}$ Delacour (2001: 257) notes that the equations voluntary $=$ conscious and involuntary $=$ unconscious are untenable, but although he gives a common-sense example of how a memory retrieval can be 'involuntary' but 'fully conscious', he does not ask whether a retrieval can, conversely, be voluntary but unconscious, or interrogate what it means for a retrieval to be conscious or unconscious in the first place. I suggest below that both distinctions are based on the same problematic structures.

17 Although many neurobiological processes, e.g. the release of neurotransmitters, are fundamentally non-conscious (and non-mental), this does not entail a distinction between 'mental states' as 'conscious' or 'unconscious'.

\section{References}

Throughout the article, where volume and page number alone are cited refer to the following edition of the book: 
Proust M (2002 [1913-1927]) In Search of Lost Time. 6 vols, Prendergast C (general ed.). London: Penguin.

Baars BJ, Ramamurthy U and Franklin S (2007) How deliberate, spontaneous, and unwanted memories emerge in a computational model of consciousness. In: Mace JH (ed.) Involuntary Memory. Malden, MA: Blackwell, 177-207.

Ball CT (2007) Can we elicit involuntary autobiographical memories in the laboratory? In: Mace JH (ed.) Involuntary Memory. Malden, MA: Blackwell, 127-52.

Ball CT, Mace JH and Corona H (2007) Cues to the gusts of memory. In: Mace JH (ed.) Involuntary Memory. Malden, MA: Blackwell, 113-126.

Barthes R (1986) The reality effect. In: Barthes $\mathrm{R}$ The Rustle of Language. Translated by $\mathrm{R}$ Howard. Oxford: Blackwell, 141-48.

Bartlett, FC (1932) Remembering: A Study in Experimental and Social Psychology. Cambridge: Cambridge University Press.

Berntsen D (1998) Voluntary and involuntary access to autobiographical memory. Memory 6: $113-41$.

Berntsen D (2007) Involuntary autobiographical memories: Speculations, findings, and an attempt to integrate them. In: Mace JH (ed.) Involuntary Memory. Malden, MA: Blackwell, 20-49.

Blackmore S (2005) Consciousness: A Very Short Introduction. Oxford: Oxford University Press.

Bogousslavsky J and Walusinski O (2009) Proust and Paul Sollier: The involuntary memory connection. Schweizer Archiv für Neurologie und Psychiatrie 4: 130-36.

Bornstein RF (1989) Exposure and affect: Overview and meta-analysis of research, 19681987. Psychological Bulletin 106: 265-89. 
Brockmeier J (2010) After the archive: remapping memory. Culture and Psychology 16: 535.

Burton J (2008) Bergson's non-archival theory of memory. Memory Studies 1: 321-39.

Chu S and Downes JJ (2000a) Odour-evoked autobiographical memories: Psychological investigations of Proustian phenomena. Chemical Senses 25: 111-16.

Chu S and Downes JJ (2000b) Long live Proust: The odour-cued autobiographical memory bump. Cognition 75: B41-B50.

Chu S and Downes JJ (2002) Proust nose best: Odors are better cues of autobiographical memory. Memory and Cognition 30: 511-18.

Churchland PM (1981) Eliminative materialism and the propositional attitudes. Journal of Philosophy 78: 67-90.

Conway MA (1996) Autobiographical memories and autobiographical knowledge. In: Rubin DC (ed.) Remembering Our Past: Studies in Autobiographical Memory. New York: Cambridge University Press, 67-93.

Conway MA (2005) Memory and the self. Journal of Memory and Language 53: 594-628.

Conway MA and Pleydell-Pearce C (2000) The construction of autobiographical memories in the self-memory system. Psychological Review 107: 261-88.

Delacour J (2001) Proust's contribution to the psychology of memory: The réminiscences from the standpoint of cognitive science. Theory \& Psychology 11: 255.

Dennett DC (1991) Consciousness Explained. Boston: Little, Brown.

Ebbinghaus H (1885) Über das Gedächtnis: Untersuchungen zur experimentellen Psychologie. Leipzig: Duncker \& Humblot.

Ender E (2005) Architexts of Memory: Literature, Science, and Autobiography. Ann Arbor: University of Michigan Press. 
Engen T and Ross BM (1973) Long-term memory of odors with and without verbal descriptions. Journal of Experimental Psychology 2: 221-27.

Epstein R (2004) Consciousness, art, and the brain: Lessons from Marcel Proust. Consciousness and Cognition 13: 213-240.

Fletcher GJO (1995) The Scientific Credibility of Folk Psychology. Mahwah, NJ: Lawrence Erlbaum.

Genette G (1980) Narrative Discourse: An Essay in Method. Translated by JE Lewin. Ithaca, NY: Cornell University Press.

Hall NM (2007) Experimental induction of involuntary memories. In: Mace JH (ed.) Involuntary Memory. Malden, MA: Blackwell, 153-76.

Herz RS and Cupchik GC (1992) An experimental characterization of odor-evoked memories in humans. Chemical Senses 17: 519-28.

Herz RS and Engen T (1996) Odor memory: Review and analysis. Psychonomic Bulletin \& Review 96: 300-13.

Herz RS and Schooler JW (2002) A naturalistic study of autobiographical memories evoked by olfactory and visual cues: Testing the Proustian hypothesis. American Journal of Psychology 115: 21-32.

Holmes E and Hackmann A (eds) (2004) Mental Imagery and Memory in Psychopathology. Special issue: Memory 12 (4).

Jackson E (1966) L’Évolution de la mémoire involontaire dans l'œeuvre de Marcel Proust. Paris: Nizet.

James W (1891) The Principles of Psychology, 2 vols. London: Macmillan.

Jellinek JS (2004) Proust remembered: Has Proust's account of odor-cued autobiographical memory recall really been investigated? Chemical Senses 29: 455-58. 
Jordan J (2001) The unconscious. In: Bales R (ed.) The Cambridge Companion to Proust. Cambridge: Cambridge University Press, 100-16.

Kolb P and Price LB (eds) Textes retrouvés. Urbana: University of Illinois Press.

Kringelbach ML (2005) The human orbitofrontal cortex: Linking reward to hedonic experience. Nature Reviews Neuroscience 6: 691-702.

Kuhn TS (1996) The Structure of Scientific Revolutions. Chicago: University of Chicago Press.

Laird DA (1935) What can you do with your nose? Scientific Monthly 41:126-30.

Lakoff G and Johnson M (2003 [1980]) Metaphors We Live By. Chicago: University of Chicago Press.

Lawless H and Engen T (1977) Associations to odors: Interference, mnemonics, and verbal labeling. Journal of Experimental Psychology: Human Learning and Memory 3: 52-59.

Lehrer J (2011) Proust Was a Neuroscientist. Edinburgh: Canongate.

Lennon TM (2007) Proust and the phenomenology of memory. Philosophy and Literature 31: 52-66.

Linde C (1987) Explanatory systems in oral life stories. In: Holland DC and Quinn N (eds) Cultural Models in Language and Thought. Cambridge: Cambridge University Press, 343-68.

Mace JH (2004) Involuntary autobiographical memories are highly dependent on abstract cuing: The Proustian view is incorrect. Applied Cognitive Psychology 18: 893-99.

Mace JH (2005) Priming involuntary autobiographical memories. Memory 13: 874-84.

Mace JH (2007) Does involuntary remembering occur during voluntary remembering? In: Mace JH (ed.) Involuntary Memory. Malden, MA: Blackwell, 50-67. 
Mandler G (1994) Hypermnesia, incubation, and mind popping: On remembering without really trying. In: Umiltà $\mathrm{C}$ and Moscovitch $\mathrm{M}$ (eds) Attention and Performance $\mathrm{XV}$ : Conscious and Nonconscious Information Processing. Cambridge, MA: MIT, 3-34.

Mandler G (2007) Involuntary memories: Variations on the unexpected. In: Mace JH (ed.) Involuntary Memory. Malden, MA: Blackwell, 208-23.

Nahmias E (2005) Agency, authorship, and illusion. Consciousness and Cognition 14: 77185.

Nalbantian S (2003) Memory in Literature: From Rousseau to Neuroscience. Basingstoke: Palgrave Macmillan.

O’Brien J (1970) Proust confirmed by neurosurgery. PMLA 85: 295-97.

Ohreen DE (2004) The Scope and Limits of Folk Psychology; A Socio-Linguistic Approach. Berne: Peter Lang.

Post F (1994) Creativity and psychopathology: A study of 291 world-famous men. British Journal of Psychiatry 165: 22-34.

Rogers BG (1965) Proust's Narrative Techniques. Geneva: Droz.

Rosch E (1977) Classification of real-world objects: Origins and representations in cognition. In: Johnson-Laird PN and Wason PC (eds) Thinking: Readings in Cognitive Science. Cambridge: Cambridge University Press.

Rubin DC, Groth E and Goldsmith DJ (1984) Olfactory cuing of autobiographical memory. American Journal of Psychology 97: 493-507.

Schacter DL and Addis DR (2007) The cognitive neuroscience of constructive memory: Remembering the past and imagining the future. Philosophical Transactions of the Royal Society 362: 773-86. 
Schlagman S and Kvavilashvili L (2008) Involuntary autobiographical memories in and outside the laboratory: How different are they from voluntary autobiographical memories? Memory \& Cognition 36: 920-32.

Shepherd GM (2006) Smell images and the flavour system in the human brain. Nature 444: 316-21.

Shepherd-Barr K and Shepherd GM (1998) Madeleines and neuromodernism: Reassessing mechanisms of autobiographical memory in Proust. Auto/Biography Studies 13: 39-60.

Solomun S (2011) A Mobile Army of Metaphors: Archiving, Sharing, and Distributing the Social in Digital Photography. Master's dissertation, Queen's University, Ontario. Abstract and excerpt available at: http://hdl.handle.net/1974/6825.

Soon CS, Brass M, Heinze H-J and Haynes J-D (2008) Unconscious determinants of free decisions in the human brain. Nature Neuroscience 11: 543-45.

Stevenson RJ and Boakes RA (2003) A mnemonic theory of odor perception. Psychological Review 110: 340-364.

Sulmont C, Issanchou S and Köster EP (2002) Selection of odorants for memory tests on the basis of familiarity, perceived complexity, pleasantness, similarity and identification. Chemical Senses 27: 307-17.

Terdiman R (1993) Present Past: Modernity and the Memory Crisis. Ithaca, NY: Cornell University Press.

Troscianko E (2010) Kafkaesque worlds in real time. Language and Literature 19: 151-71.

Troscianko E (forthcoming 2012) The cognitive realism of memory in Flaubert's Madame Bovary. Modern Language Review 107: 775-99.

Turkle S (2007) What makes an object evocative? In: Turkle S (ed.) Evocative Objects: Things We Think With. Cambridge, MA: MIT, 307-27. 
Utermohlen V (2002) Was Proust a taster? Taste sensitivity to 6-n-propylthiouracil and the relationships among memory, imagination, synesthesia, and emotional response to visual experience. Food and Foodways 10: 99-109.

Watkins MJ (1990) Mediationism and the obfuscation of memory. American Psychologist 45: 328-35.

Wegner DM and Wheatley T (1999) Apparent mental causation: Sources of the experience of will. American Psychologist 54: 480-92.

Zéphir JJ (1959) La Personnalité humaine dans l'oeuvre de Marcel Proust: Essai de psychologie littéraire. Paris: Lettres Modernes.

\section{Author biography}

Emily Troscianko is currently Junior Research Fellow in Modern Languages at St John's College, Oxford, and an Associate Researcher with the Balzan Interdisciplinary Seminar 'Literature as an Object of Knowledge'. Her doctoral thesis explored Kafka's fiction in relation to pictorialist and enactivist theories of vision, and she is now investigating the evocation of other areas of cognition in French and German 'Realist' and 'Modernist' literature, with the broad aim of illuminating literary Realism from a cognitive perspective. 